\title{
LA TERRE DE FEU (1925): UN DOCUMENTAL FRANCÉS SOBRE LOS INDÍGENAS DE PATAGONIA Y TIERRA DEL FUEGO
}

\author{
DOMINIQUE LEGOUPIL ${ }^{a} \&$ DENIS CHEVALLAY ${ }^{b}$
}

\begin{abstract}
RESUMEN
Este artículo trata de una película muda filmada en abril y mayo de 1925, durante una expedición en barco en Patagonia y Tierra del Fuego, organizada por la Sociedad francesa de Geografía. Solo queda una copia parcial de 33 minutos, la que fue redescubierta hace poco y restaurada por el CNC (Centre National du Cinema) en Francia. La película muestra tres grupos indígenas. En una larga secuencia de casi 20 minutos se puede ver la vida cotidiana de los alacalufes (kawésqar), poco conocidos y viviendo aislados en los canales. Los vemos navegando, construyendo su choza, comiendo mariscos, etc. Otra secuencia más breve concierne a los yaganes (o yámana) del canal Beagle, más conocidos en particular por las fotos del etnólogo M. Gusinde. Finalmente se ven unas imágenes fugaces de los selk'nam (u onas) en las estepas de Tierra del Fuego.
\end{abstract}

PALABRAS CLAVE: filmación, Castelnau, alacaluf, yagan, selk'nam, Patagonia, Tierra del Fuego.

\section{LA TERRE DE FEU (1925): A FRENCH DOCUMENTARY ABOUT THE INDIGENOUS PEOPLE OF PATAGONIA AND TIERRA DEL FUEGO}

\begin{abstract}
This article deals with a mute movie shot in April and May 1925, during a boat expedition in Patagonia and Tierra del Fuego, organized by the French Geography Society. There is only one partial copy of 37 minutes left, which was recently rediscovered and restored by the CNC (Centre National du Cinema) in France. The film shows three indigenous groups. In a long sequence of almost 20 minutes you can see the daily life of the alacalufes (kawésqar), little known and living isolated in the channels. We see them sailing, building their hut, eating seafood, etc. Another shorter sequence concerns the Yaganes (or yamana) of the Beagle Channel, better known in particular by the photos of ethnologist M. Gusinde. Finally, there are fleeting images of selk'nam (or onas) in the steppes of Tierra del Fuego.
\end{abstract}

KEY WORDS: film, Castelnau, alacaluf, yagan, selk'nam, Patagonia, Tierra del Fuego.

a Directora de investigación emérita, Etnografía prehistórica (UMR 7041), Centre National de la Recherche Scientifique (CNRS), Francia. dominique.legoupil@cnrs.fr

b Investigador, Fuegia \& Co., Puerto Williams, Chile. denischevallay@gmail.com 


\section{INTRODUCCIÓN}

La Terre de Feu es un documental francés, en formato $35 \mathrm{~mm}$, mudo y tintado, que fue filmado entre abril y mayo de 1925 en Patagonia austral y Tierra del Fuego, y distribuido en Francia el año siguiente por la empresa Aubert. Tuvo un retundo éxito, particularmente cuando se proyectó con acompañamiento musical en Paris en el teatro del Vieux Colombier, antes de caer en el olvido (Fig. 1).

Una copia parcial en acetato de 33 minutos de duración (lo que representa menos de la mitad de la película original) fue recientemente redescubierta por la cinemateca de Toulouse y restaurada por el Centre National du Cinéma en Bois d'Arcy, ambos en Francia. La primera parte de la filmación falta por completo y en la segunda, se notan numerosos cortes. El negativo en nitrato no se conservó, al igual que los numerosos rush desde los cuales se montó la película.

La filmación fue realizada por Paul Castelnau, geógrafo y fotógrafo reconocido por sus placas autocromas (los autochromes de los hermanos Lumière), tomadas durante la primera guerra mundial, y su participación en la primera travesía del Sahara en vehículo. También como realizador, el documental cuenta con Lucien Le Saint, un famoso operador cinematográfico de la firma Gaumont y de la fundación A. Kahn y sus Archives de la Planète. Ambos fueron mandados por la Société de Géographie Française. El otro director, Joseph Mandement, era un prehistoriador francés que había distribuido en 1925 la película etnográfica Nanouk de Flaherty, agregando una introducción que establece una comparación entre esquimales y hombres prehistóricos. Para La Terre de Feu, Mandement había escrito un guion (Mandement, s.f.) basado en los trabajos de la Mission Scientifique du Cap Horn o Misión de la Romanche (Martial, 1888; Hyades \& Deniker, 1891), pero por falta de imágenes adecuadas, no fue realmente aplicado. Debido a que Mandement no participó en el rodaje en terreno, suponemos que su papel se concentró en la post producción de la película, lo que explicaría, además de los recortes que notamos, las incoherencias de la versión que conocemos hoy. El muy instructivo diario

$1 \quad$ L'impossibilité [...] de filmer de vrais sauvages encore à l'état sauvage armés non de silex, mais de couteaux de provenance européenne, allant au gré des îlots, non dans une pirogue en écorce d'arbre, mais dans un mauvais

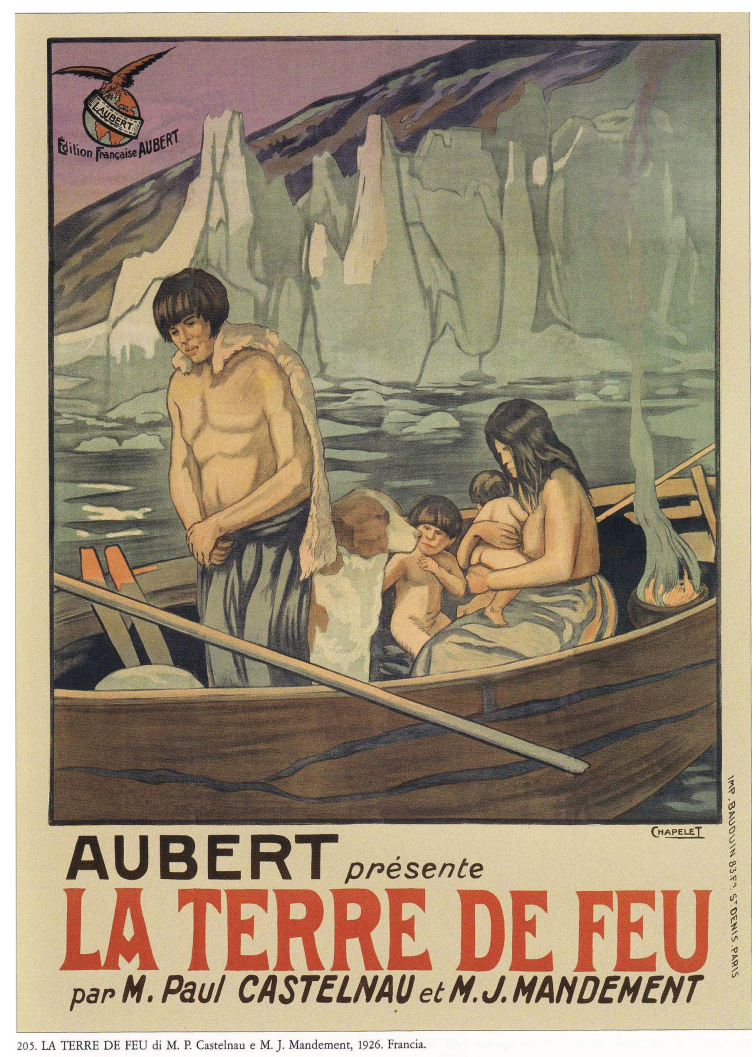

Fig. 1. El afiche de la película La Terre de Feu, por Chapelet (litografía, 1926).

personal de Le Saint (1925) permitió reconstituir la cronología y el itinerario del viaje y, por ende, rectificar algunos errores, como por ejemplo los lugares o las interpretaciones de algunas escenas.

Los comentarios presentados en los subtítulos reflejan los prejuicios etnocentristas de la época. En lo que se refiere a las imágenes, se notan puestas en escena intencionales asumidas por Mandement, quien resaltaba: la imposibilidad [...] de filmar verdaderos salvajes aún en un estado salvaje [nombra específicamente a los alacalufes] armados no de pedernal pero de cuchillos de procedencia europea, vagando entre islotes, no en canoa de corteza pero en una pobre canoa hecha de tablas, [...] sabiendo construir las chozas ancestrales pero utilizando herramientas modernas ${ }^{1}$ (Mandement, 1929, p. 539) 2 . Concluye que hay por ende que apurarse de

canot fait de planches [...] sachant construire la hutte ancestrale, mais au moyen d'outils modernes.

2 Todas las traducciones de citas son nuestras. 
recolectar los documentos etnográficos antes de la desaparición completa de las antiguas usanzas y costumbres, y estamos a veces obligados, para las películas documentales, a falsificar en alguna medida las escenas ${ }^{3}$ (Ibid.).

De hecho, la mayor parte de los documentos de antropología visual de esta época contienen puestas en escena más o menos asumidas, por dos razones: primero, para responder a las exigencias técnicas de la fotografía que necesitaba una completa inmovilidad de los sujetos para obtener una imagen bien enfocada y, segundo, porque desde hacía más de tres décadas la mayor parte de los indígenas (los del canal Beagle incluidos) tenía un estilo de vida ya europeizado. Sin embargo, y contrariamente a $\mathrm{La}$ Terre de Feu, las representaciones de autóctonos más conocidas están acompañadas por verdaderas indagaciones etnográficas. Es el caso en particular de Martin Gusinde, quien tomó numerosas fotografías entre 1919 y 1924, e igualmente, pero en menor medida, A. M. De Agostini quien, además de sus fotografías (De Agostini, 1945), integrará imágenes animadas de la vida indígena en su película Tierra del Fuego. Esta película se proyectó por primera vez en Punta Arenas en 1928 y en Italia bajo el nombre de Terre Magellaniche en 1933 (Chevallay \& Granero, 2013, pp. 142-43). Pero la mayor parte de estos documentos representan selk'nam y yaganes más o menos sedentarios en la parte sur de Tierra del Fuego, a los cuales los etnólogos hacen actuar en escenas reconstituidas: Gusinde no tomaba meras fotografías de lo que veía, sino que reconstruía, con ayuda de los indios, escenas de una vida diaria en gran medida desaparecida (Palma, 2015, p.23). Muy pocos muestran a alacalufes ${ }^{4}$ como los únicos que seguían con su vida nómade, protegidos de la colonización pastoril (pero no de los balleneros y loberos) en el laberinto de los archipiélagos de la Patagonia occidental. Ellos fueron fotografiados en muy contadas ocasiones por navegantes y viajeros como Carl Skottsberg en los años 1908-1909 (Skottsberg, 1911) pero, hasta donde sabemos, las únicas imágenes animadas que muestran a alacalufes

3 Il faut en conséquence se hâter de recueillir les documents ethnographiques, avant la disparition totale des anciennes moeurs et coutumes, et l'on est parfois déjà obligés, pour les films documentaires, de truquer quelque peu les scènes.

4 "alacaluf" es el nombre utilizado en la etnografía tradicional del siglo XIX e inicios del XX para los indígenas canoeros quienes vivían entre el estrecho de Magallanes y el golfo de de esta época son las de De Agostini que aparecen en su Tierra del Fuego y donde se ve, en una escena de 2 minutos filmada en Puerto Edén, una canoa abordar un buque y algunos indígenas subir a bordo.

\section{LA EXPEDICIÓN: ITINERARIO Y ENCUENTROS CON VARIOS GRUPOS DE INDÍGENAS}

La película La Terre de Feu fue rodada durante una expedición marítima efectuada con el cutter Júpiter a vela y motor de 9 toneladas, fletado en esta oportunidad en la ciudad de Punta Arenas, Chile (Fig. 2a). El viaje duró 50 días según el diario del piloto, Albert Pagels, y más precisamente desde el 16 de marzo hasta el 4 de mayo según el diario de Le Saint.

Pagels (Fig. 2b), gran conocedor de los canales patagónicos y fueguinos había acompañado la expedición de Otto Nordenskjöld y guió al crucero de guerra alemán Dresden en el archipiélago fueguino durante la primera guerra mundial. Llevó luego a la misión Castelnau desde Punta Arenas hasta el cabo de Hornos, pasando por el pequeño depósito carbonero de Puerto Ramírez en la península Muñoz Gamero (y no en la isla Clarence como está indicado en la película), donde los cineastas pudieron filmar un grupo de alacalufes. Prosiguieron hasta la ciudad de Ushuaia (Argentina) donde recalaron en dos oportunidades, de ida y de vuelta, filmando brevemente a los yaganes que vivían en las cercanías (Fig. 3).

Los glaciares, que fascinaban a los viajeros, aparecen de vez en cuando en la película. Nombraremos aquí algunos que hemos podido identificar: el Negri (en el fiordo homónimo), el Italia y el Holanda, ambos en el brazo nordeste del canal Beagle.

El recorrido marítimo se terminó en Punta Arenas después de una breve recalada en la isla Dawson, donde un aserradero había reemplazado la misión salesiana San Rafael. En la misión fueron concentrados y murieron numerosos alacalufes y selk'nam entre 1891 y 1911. No obstante,

Penas, mientras "kawesqar" es el nombre reivindicado desde los trabajos etnográficos de J. Emperaire por el reducido grupo de Puerto Edén y sus descendientes (Emperaire 1955, p. 229). Las dos denominaciones se utilizan a menudo como sinónimos. En este artículo, conservamos la palabra "alacaluf" que se usa en la película, la única utilizada en el tiempo de Castelnau. 

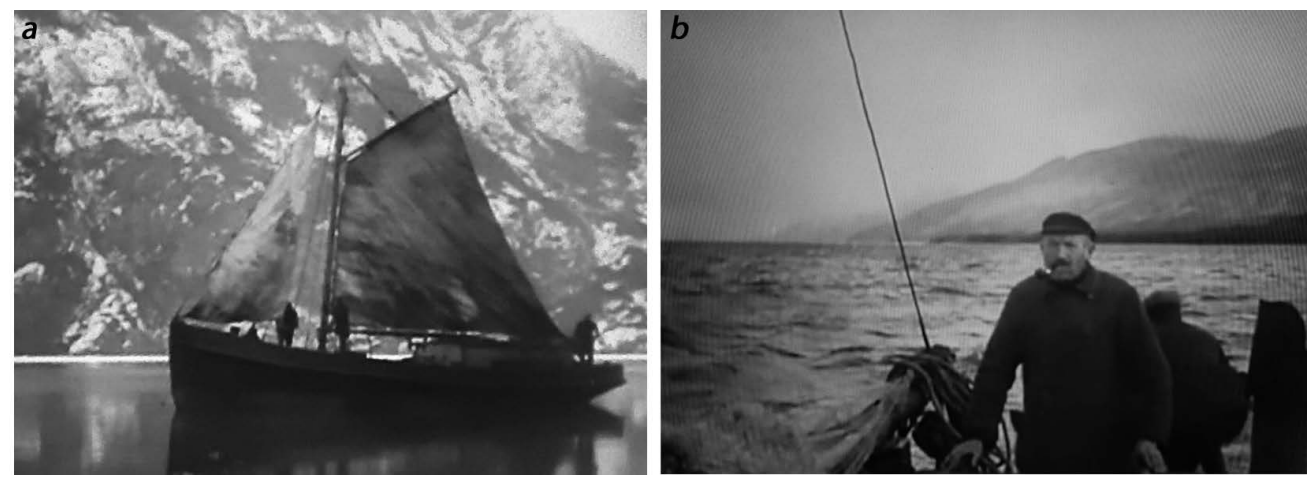

Fig. 2. La expedición: 2a) El Júpiter durante la expedición;

2b) El piloto A. Pagels a bordo del Júpiter (fotogramas de la película La Terre de Feu).

ninguna imagen de este establecimiento aparece en la película. Según Le Saint, después del retorno de la expedición a Punta Arenas, Castelnau viajó solo a Río Grande en Tierra del Fuego, Argentina. Es en esta zona que filmó a los selk'nam que se ven hacia el final de la película.
Tres grupos étnicos, actualmente representados por muy pocos individuos, están por ende presentes de manera muy desigual en la película. Los nómades canoeros alacalufes aparecen durante unos 20 minutos y los yaganes durante 2 minutos, al igual que los cazadores pedestres selk'nam.

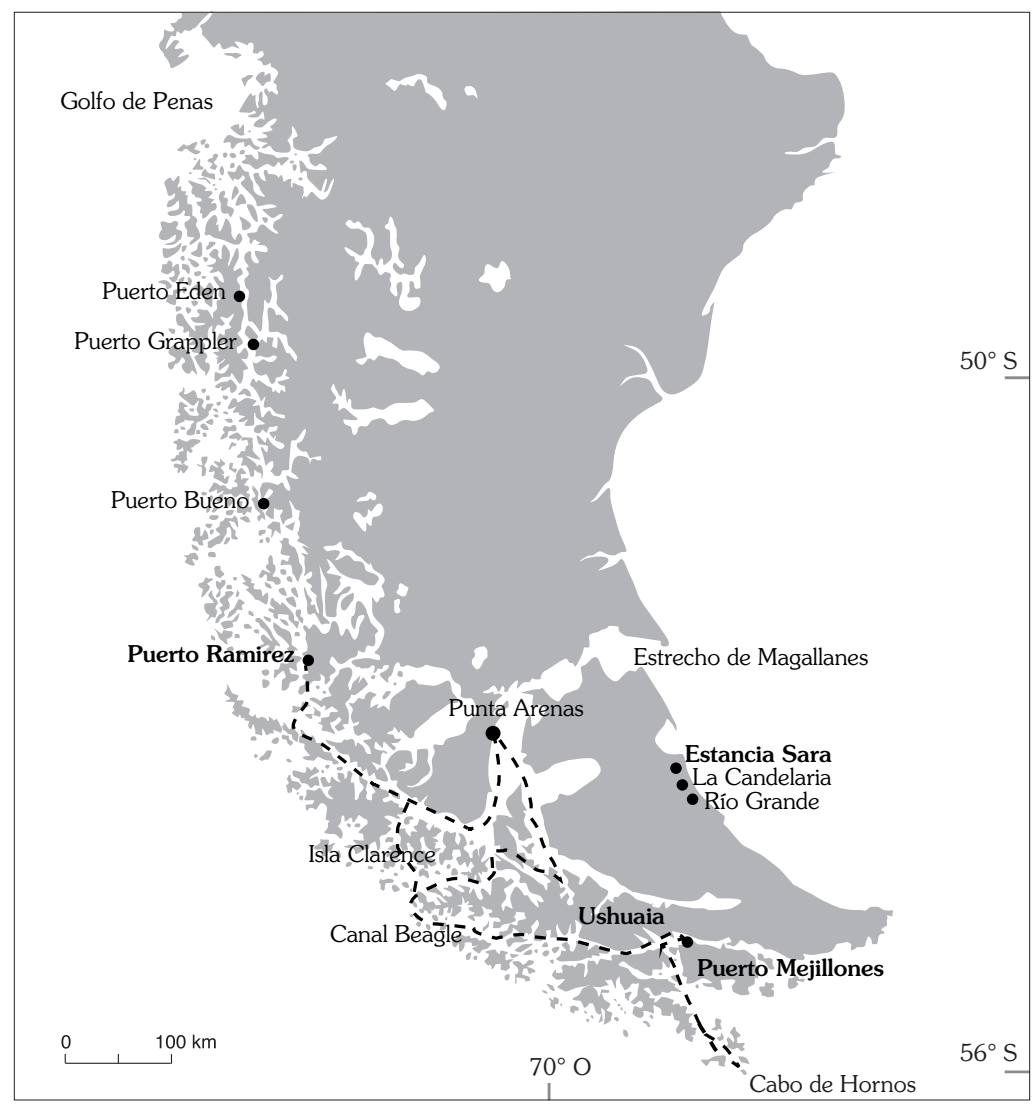

Fig. 3 Reconstitución del itinerario de la expedición Castelnau (línea de puntos) y principales sitios de encuentros con indígenas (en negrita). 
LOS ALACALUFES DE PUERTO RAMÍREZ: UNA DE LAS POCAS FILMACIONES DE LA VIDA NÓMADE EN LOS ARCHIPIÉLAGOS

La secuencia que muestra a los alacalufes es, entonces, la más larga. Se ve en ella la llegada de una decena de personas y algunos perros a bordo de dos canoas en una playa cercana al depósito de carbón de Puerto Ramirez. Este fue instalado en el canal Smith a inicios del siglo XX, pocos años antes del paso de Skottsberg (1911). Estaba destinado a abastecer los buques de la Armada de Chile que seguían la ruta de los canales y se ubicaba inmediatamente al sudeste de la isla Longa, sobre la península Muñoz Gamero, a 52 ${ }^{\circ} 19^{\prime}$ Sur y $73^{\circ} 33^{\prime}$ 'Oeste (Riso Patrón, 1924; Atlas Hidrográfico de Chile, 1989, mapa 1008). Un pequeño cementerio histórico fue descubierto en este lugar hace algunos años (cfr. Chevallay, 2000).

En el mismo lugar, Gusinde efectuó el registro de sus datos sobre los alacalufes, durante una estadía de cuatro meses (octubre 1923 a enero 1924). Estos datos aparecen en la última parte de su obra Die Feuerland Indianer, la que se publicó de manera póstuma, después de que se reconstituyeron los archivos del autor que fueron quemados al final de la segunda guerra mundial (Gusinde, 1991 [1974]). $\mathrm{Si}$ bien las informaciones contenidas en este tercer tomo no tienen el mismo valor que los dos primeros volúmenes consagrados a los yaganes y selk'nam, ciertos datos resultan útiles para complementar las imágenes filmadas poco tiempo después por la expedición Castelnau.

En 1904 la población de los alacalufes se estimaba en unos 800 individuos (Barclay, 1904). Veinte años después este número se redujo a 120 personas, las que se distribuían principalmente en dos grupos (De Agostini, 1945). El primero, hacia el norte, se concentraba en Puerto Edén donde De Agostini no pudo más que filmar y fotografiar brevemente algunos individuos ya que gran parte del grupo estaba en una expedición de pesca en la costa oeste de la isla Wellington. El segundo grupo se ubicaba más hacia el sur, en el área de la península Muñoz Gamero (Ibid.). Es este grupo que fue fotografiado por Gusinde y filmado por Castelnau. Durante la estadía de Gusinde en Puerto Ramírez se reconoce el paso de alrededor de 70 adultos. Esto da cuenta de la importancia de esta pequeña población meridional, incluso en 1924-25, y que se supone tenía su centro de actividades sobre la vecina isla Longa, población de la cual Castelnau no reparó en más que una pequeña fracción.

Entre estas dos zonas separadas por unos $400 \mathrm{~km}$, otras dos bahías jugaron probablemente un papel importante en los desplazamientos de los últimos nómades canoeros de las primeras décadas del siglo XX: Puerto Bueno, señalado a la vez por Gusinde y Skottsberg, y Puerto Grappler. Este último estaba ocupado en 1908 por el grupo más grande de indígenas que hemos visto ${ }^{5}$ (Skottsberg 1911, p.85), o sea una treintena de personas quienes usaban un idioma un poco diferente del practicado más al sur (Ibid.). La pequeña población de Puerto Edén fue el objeto de un trabajo etnográfico 20 años más tarde, es decir en 1946/47. En ese entonces, el total de los alacalufes diseminados en los archipiélagos representaba todavía un centenar de personas, y en 1953, se redujo a 61 individuos (Emperaire, 1963, p. XV).

La película muestra imágenes poco frecuentes de estos últimos nómades marítimos que deambulaban en esta región desde al menos 4500 años, y probablemente más, como lo demuestra una sepultura encontrada en la isla Madre de Dios (Legoupil \& Sellier, 2004). En la filmación podemos ver canoas, la construcción de una choza y diversas escenas de la vida cotidiana, además de algunas escenas "rituales" sobre las cuales es difícil resolver su autenticidad por ser, probablemente, expresamente a pedido de los cineastas.

\section{La canoa de tablas:}

¿influencia de la dalca de los loberos chilotes?

Las canoas que podemos ver en la película están constituidas por un fondo tallado en un tronco de árbol, al estilo de las embarcaciones monóxilas, y reforzadas por tres tablas clavadas que evocan la dalca de tablas característica de Chiloé (Fig. 4a). Este tipo de embarcación parece haber reemplazado, al final del siglo XIX y especialmente a principios del XX, a la canoa de corteza tradicional, probablemente bajo la influencia de los loberos. Un examen atento de estas imágenes demuestra las peculiaridades de estas canoas: el ensamblaje de las piezas con clavos (Fig. 4b), la propulsión ya no más por medio de pagayas cortas, sino que por remos encastrados en dos piezas

\footnotetext{
5 the largest party of indians we saw.
} 


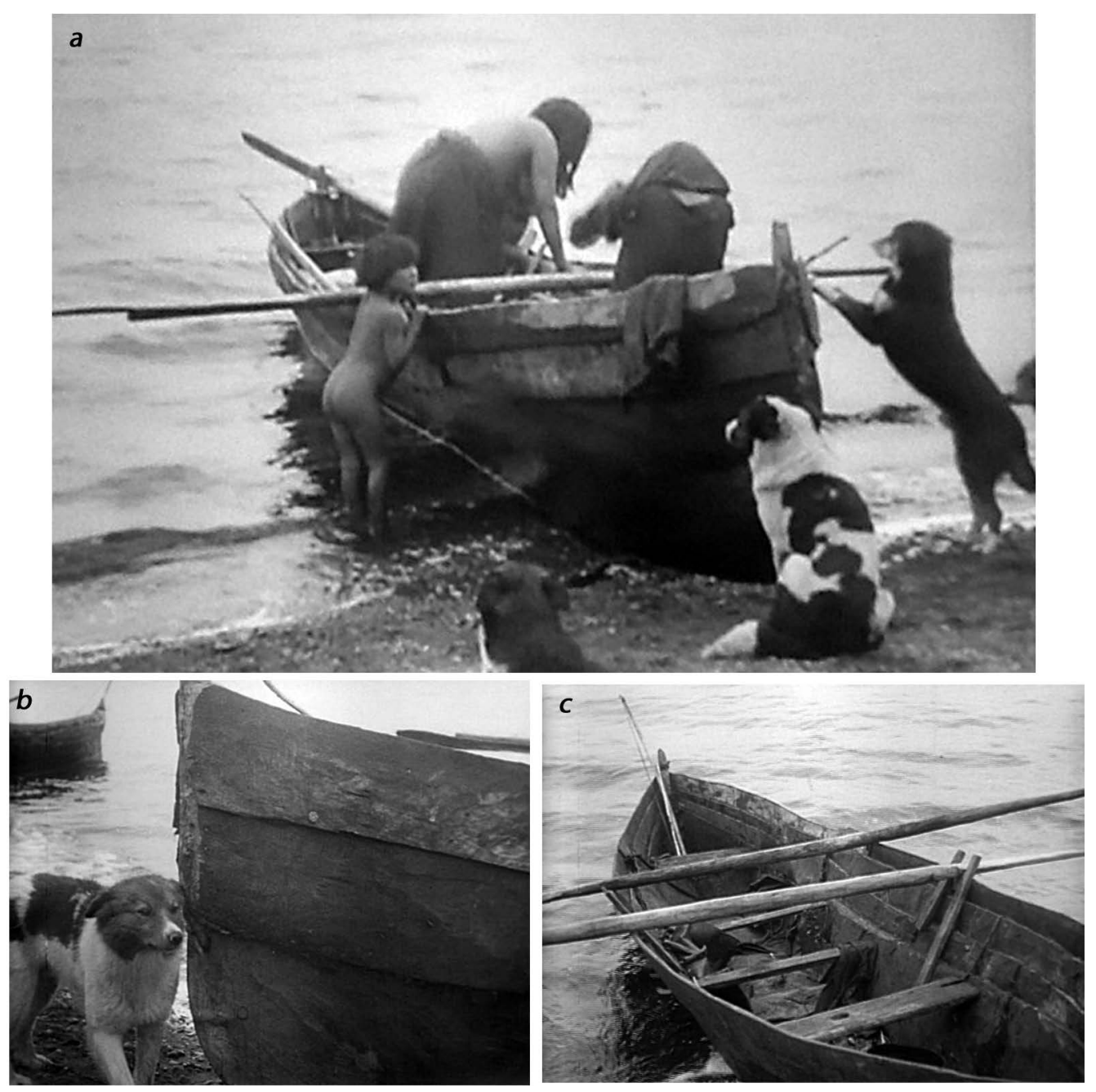

Fig. 4. La canoa: a) vista de conjunto desde la proa; b) detalle de la proa; c) vista del interior del casco (fotogramas de la película La Terre de Feu).

verticales de maderas que cumplen la función de un escálamo o chumacera rudimentaria, al igual que el remo de timón en popa, mientras el banco central tiene un orificio que parece ser una fogonadura para sostener un pequeño mástil, y por ende permitir la navegación a vela (Fig. 4c).

\section{Instalación y construcción de la choza}

El emplazamiento del campamento resulta ser la elección de los cineastas. Según Le Saint, los indígenas, cuya principal actividad consistía desde hacía varias décadas en el trueque de pieles con los loberos, acampaban en una caleta cercana conocida como bahía de Ouake. Aceptaron desplazarse hacia las cercanías del depósito de carbón, no sin dificultad y con la contraparte de numerosos regalos, sobre todo de cigarrillos y alcohol, además de dos lobos cazados por los marinos. La choza se ubica sobre la playa, a orilla del bosque, en un lugar bastante despejado y bien adaptado a las necesidades de los cineastas, pero sorprendentemente cercano a la línea de alta marea. Las pocas fotografías de chozas que Gusinde había tomado un año antes en el mismo sector, mostraban que estaban generalmente instaladas a una mayor distancia del mar y en medio de la vegetación, después de una limpieza sumaria de los arbustos (Gusinde, 1991, figs. 3, 4, 5).

La construcción corresponde bastante fielmente alas numerosas perobreves descripciones 

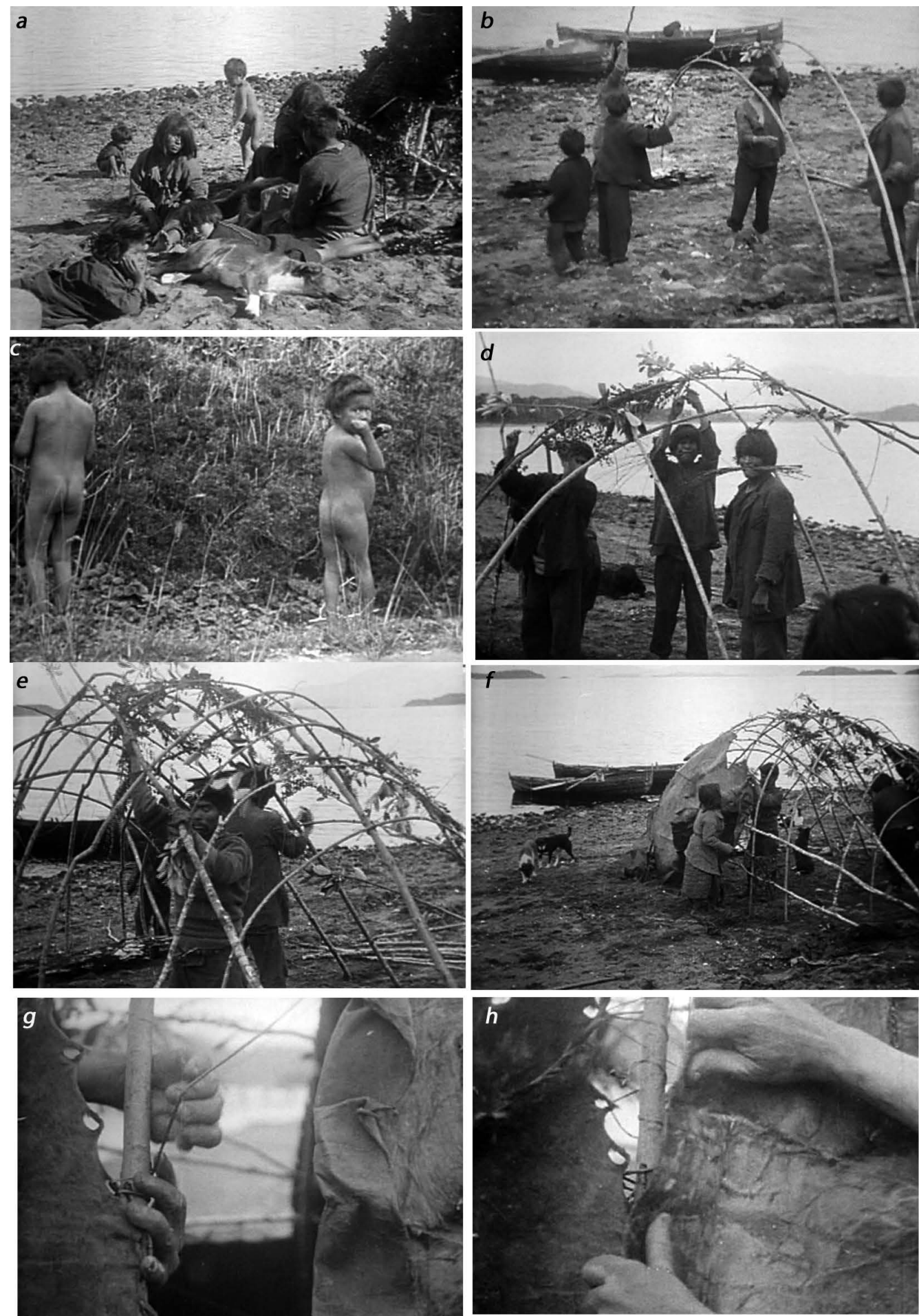

Fig. 5 La construcción de la choza: a) un niño golpea el suelo con un bastón; b) la instalación de los dos arcos de bóveda; c) la cosecha de los juncos para atar las varas (el niño de la derecha los ablanda con los dientes en un gesto ancestral); d, e) atando las varas hechas con canelo (Drymis winteri); $\mathrm{f}, \mathrm{g}$, h) la fijación de las pieles (fotogramas de la película La Terre de Feu). 
de los navegantes de los siglos pasados y de los etnólogos del siglo XX (Skottsberg, 1911; Emperaire, 1963 [1955]; Gusinde, 1991 [1974]). En la película se observa un niño que golpea la punta de un bastón sobre el suelo. ¿Quizás está imitando un gesto de los adultos como la limpieza del suelo o un movimiento de arpón? (Fig. 5a). La construcción empieza con el montaje de dos arcos de bóveda hechos con ramas flexibles y lisas que son juntadas de a dos y luego plantadas en el suelo (Fig. 5b). Sobre esta base estructural gradualmente se fija con juncos el conjunto de varas que dará flexibilidad y resistencia a la choza contra los vientos (Fig. 5c, d, e). Finalmente, se colocan las pieles preparadas con agujeros en sus bordes como si fuesen ojales (Fig. 5f, 5g). Las grandes dimensiones de estas pieles indican que provienen probablemente de lobos de un pelo (Otaria flavescens).

\section{El transporte del fuego}

Una vez lista la choza, el fuego que estaba conservándose en la canoa es transportado en un pequeño balde metálico hasta la choza por una anciana (Fig. 6a y 6b). Un año antes, Gusinde había fotografiado en Puerto Ramírez un alacalufe encendiendo una fogata por fricción de dos pedazos de madera (Fig. 6c). No obstante, enfatiza que esta técnica sería un recurso último utilizado muy excepcionalmente y cabe preguntarse si la fotografía no corresponde, otra vez, a una puesta en escena sugerida por el etnólogo. De hecho, la producción



Fig. 6 El fuego en lo de los alacalufes de la península Muñoz Gamero:

a, b) el transporte desde la canoa hasta la choza de las brasas, en un balde metálico

(fotograma de la película La Terre de Feu); c) la producción del fuego por fricción (Gusinde, 1991, fig. 40). de fuego por medio de la percusión de pedazos de pirita es la única técnica mencionada por numerosos navegantes y J. Emperaire recalca que solo el procedimiento de percusión estaba en uso entre los alacalufes. Los testimonios de los más viejos de ellos son formales en este punto (Emperaire, 1963, p. 120). En 1946, en Puerto Edén, los fósforos estaban ya en uso y constituían incluso una de las pocas pertenencias conservadas con sumo cuidado (Ibid.).

\section{El problema del arco}

La construcción de la choza se termina con un supuesto ritual para alejar a los espíritus malignos. Esta extraña escena muestra a los hombres con un arco entrando uno por uno en la choza (Fig. 7) y saliendo por una pequeña abertura trasera. Parece corresponder más bien a un pedido de los cineastas y no se ratifica en ninguna otra fuente etnográfica. Igualmente, otra escena en donde un "hechicero" reproduce gestos supuestamente chamánicos y que hace aparecer en los labios de una mujer joven una sonrisa. Esto nos hace suponer que se está burlando de la credulidad de los cineastas, salvo si se trata de dos planos fílmicos distintos -las mímicas de "hechiceros" y la sonrisa de la mujer- que no tienen relación entre ellos $y$ que fueron resultado del montaje posterior de la película.




Además, por dudosa que sea, la escena de "exorcismo" de la choza permite exponer dos puntos discutidos frecuentemente. El primero, la existencia de una puerta trasera que menciona Emperaire (Ibid.) y que se reduce en la película a una pequeña abertura, probablemente opcional, a través de la cual se podía pasar levantando una piel. El segundo punto es más relevante: constatamos que los hombres de este sector tenían arcos, a pesar que esta arma se considera generalmente como típica de los cazadores terrestres y una tradición supuestamente "desconocida" por los indígenas canoeros viviendo en un entorno forestal poco propicio para su uso. Sin embargo, la presencia de numerosas y diminutas puntas líticas con pedúnculos y aletas, consideradas como típicas del uso de arco y flechas, está representada en ciertos sitios canoeros tardío-históricos de la parte occidental del estrecho de Magallanes como en Batchelor (Morello et al. 2008; Legoupil et al. 2014), al igual que en los mares interiores, por ejemplo en Punta Baja, en el seno Otway (Legoupil, 1989). En el siglo XVIII, Bougainville también había señalado su utilización por parte de los indígenas de la isla Carlos III, en el estrecho de Magallanes, y colectó una de estas armas, la que actualmente se conserva en el Museo de Quai Branly (Paris, Francia).
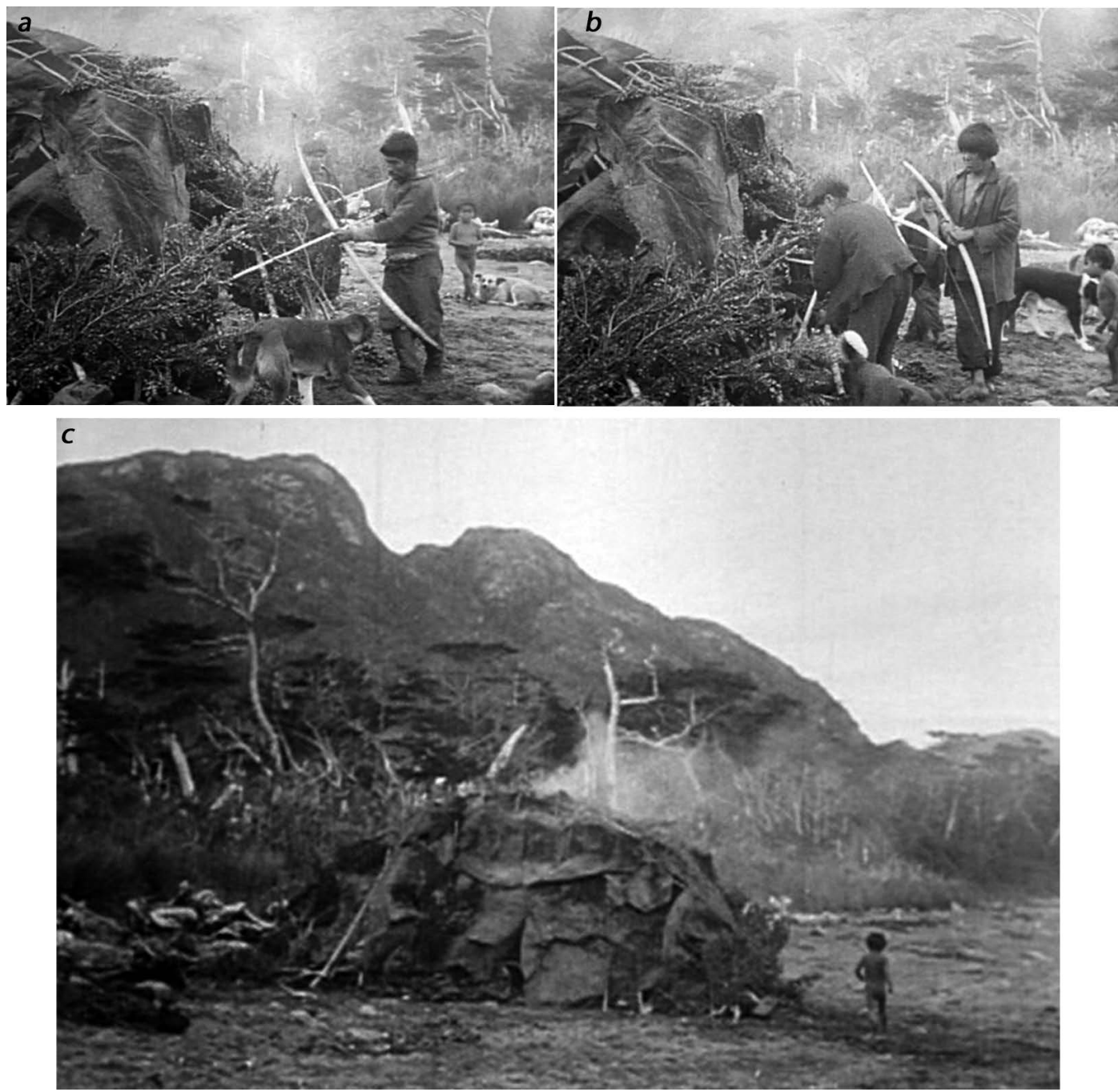

Fig. 7. Después del ritual de alejamiento de los espíritus malignos de la choza (a y b), aquella estaba lista para su uso (c) (fotograma de la película La Terre de Feu). 
Por su parte, Skottsberg reconoce indirectamente la existencia de arcos en los archipiélagos del occidente para el final de la primera década del siglo $\mathrm{XX}$, a pesar que los consideraba en desuso: Arcos y flechas parecen estar en desuso [...] Son de la misma forma que los utilizados por los Onas, pero más pequeños. Las flechas están hechas con michay (Berberis ilicifolia) con puntas muy bien hechas de piedras o vidrio 6 (Skottsberg, 1911, p. 96). En cuanto a su uso, según De Agostini (1945, p. 70): el arco y las flechas los usan únicamente para la caza del huemul. Fantasiosa o no, la escena de la película demuestra que los alacalufes de Puerto Ramírez poseían arcos de un tamaño bastante grande.

El incendio de la choza y un zarpe precipitado

La estadía de los alacalufes en Puerto Ramírez termina por una escena aparatosa (Fig. 8): la huida precipitada frente a un temporal acercándose y el incendio de la choza que correspondía, según el comentario de la película, una vez más a un ritual. Sin embargo, según Skottsberg: La choza está cubierta de pasto, hojas de helechos, ramas de árboles o con pieles de leones marinos y viejas piezas de ropa [...] las pieles de gran tamaño son naturalmente muy preciadas; nunca se dejan atrás en un campamento ${ }^{7}$ (Skottsberg, 1911, p. 94). Veinte años más tarde, Emperaire precisa: Los alacalufes se prohíben destruir las arcadas de madera de la choza que abandonan. No se llevan consigo sino las pieles de foca que la han recubierto (Emperaire, 1963, p. 77). La contradicción entre estas informaciones y la película es flagrante, pudiendo explicarse también por el diario de Le Saint. En realidad, este reconoce haber incendiado él mismo la choza, de manera accidental, con sus antorchas de manganeso. Este acontecimiento provocó un gran enojo por parte de los indígenas quienes intentaron agredirlo $y$ al día siguiente, de madrugada, se embarcaron precipitadamente. Esta reacción se puede explicar fácilmente: por una parte un tabú fue transgredido (no destruir el armazón que puede ser usado en una próxima parada) y por otra parte se destruyeron varias pieles, un bien muy valioso.

\section{EL ENCUENTRO CON LOS YAGANES DEL CANAL BEAGLE}

Los yaganes eran mejor conocidos por los etnólogos que los alacalufes y fueron fotografiados en 1882/83 por Doze y Payen durante la Mission Scientifique du Cap Horn cuando aún vivían de un modo nómade (Martial, 1888; Hyades \& Deniker, 1891). Para 1925 ya eran bastante sedentarios,
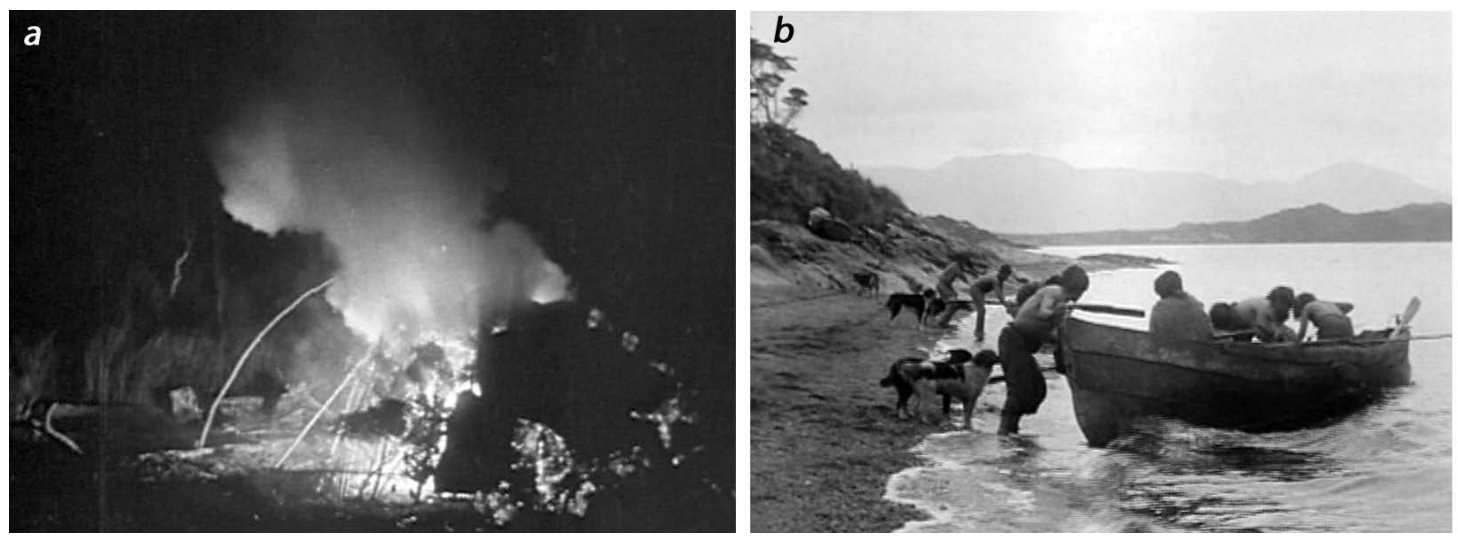

Fig. 8. El incendio de la choza en medio de la noche (a); y el zarpe en canoa durante la madrugada siguiente (b); (fotograma de la película La Terre de Feu).

6 Bows and arrows seem to have fallen out of use [...] They are of the same shape as those used by the Onas, but smaller. The arrows are made of yellow berberis-wood, and have a neatly fashioned point of flint or glass. the wigwam is covered with grass, fern-leaves, twigs of trees, or with sea-lions skins and old pieces of clothes ... the large skins are naturally much appreciated; they are never left behind on a camp place. 
habitando en los alrededores de la ciudad de Ushuaia o en las estancias de los misioneros ingleses y sus descendientes en ambas riberas del canal Beagle.

Se evoca en la filmación dos encuentros con los yaganes: primero, en el viaje de ida el $9 \mathrm{y}$ 10 de Abril de 1925 Le Saint relata: Dedicamos este día en ir a hacer tomas de un campamento de patagones ${ }^{8}$ a Mejillones, a 10 millas sobre la frontera chilena [...]. Estos indigenas son bellos hombres, inteligentes y civilizados [...]. Juntamos una documentación interesante [...], haciéndolos reproducir escenas de sus antepasados, pinturas faciales que practican todavía los días de fiesta, sus juegos, la construcción de sus chozas, menos primitivas que las de los alacalufes ${ }^{9}$ (Le Saint, p. 23). El lugar podría ser Puerto Mejillones en la costa norte de la isla Navarino o la estancia Remolino de la familia Lawrence en la costa norte del canal Beagle.

De regreso del cabo de Hornos, el 20 de Abril, Le Saint relata un segundo encuentro: Nos señalan un campamento de indigenas patagones. Vienen aqui para hacer un poco de negocios con los habitantes de la ciudad, pero no se le dan el permiso de entrar en Ushuaia. Acampan en islotes en frente y la mayor parte del tiempo los habitantes de la ciudad vienen a su encuentro, por la razón que venden de todo: cestería hecha por las mujeres, peces pescados por los hombres, ovejas y aves de corral criados por ellos ${ }^{10}$ (Ibid., p. 26). Según el arqueólogo Ernesto Piana y tres descendientes de yaganes que viven en Ushuaia, esta escena no fue filmada en los islotes frente a Ushuaia, sino que hacia la extremidad oriental de la bahía homónima, en el lugar conocido como Playa Larga, donde el cineasta pudo haber ido en barco y pensar erróneamente que estaba en una isla.

8 Sic: no se trataba evidentemente de los "patagons" de H. de Magallanes, los cuales ocupaban las estepas continentales y no Tierra del Fuego.

9 Nous occupons cette journée à aller prendre des vues d'un camp d'Indiens patagons à Mejillones, à 10 milles sur la frontière chilienne... Ces Indiens sont de beaux hommes, intelligents et civilisés ... Nous recueillons une documentation intéressante [...], leur faisant reproduire des scènes de leurs aïeux, peintures du visage qu'ils pratiquent encore les jours de grande fête, leurs jeux, le montage de leurs huttes, moins primitives que celles des alacalufs.
Varias personas que aparecen en la película fueron identificadas gracias a las fotografías de Gusinde y De Agostini: el anciano y ciego Whaits (también ortografiado según las fuentes como Witch o Weitz) aparece primero (Fig. 9d), luego las tres mujeres que empujan una canoa al agua son Ethel, Mary/Yayosh y Julia/ Carrupako le kipa (Fig. 9a); esta última está también en la escena de la caza del delfín con Chris (Fig. 9b). En un grupo de mujeres y niños, sentada a la izquierda está Peine/Ohmchen y con el pañuelo sobre la cabeza, de nuevo Julia/ Carrupako le kipa. Las dos jóvenes atrás, que aparecen en otra escena, no fueron identificadas (Fig. 9c). En la escena de las pinturas faciales (Fig. 9e), la mujer es Kerty, pintando a Chris (izquierda) y Noah (derecha) ${ }^{11}$.

\section{ALGUNAS IMÁGENES DE SELK'NAM: ANGELA LOIJ}

Las pocas imágenes de cazadores pedestres selk'nam que se pueden apreciar fugazmente al final de la película no fueron tomadas durante el viaje en barco, sino después, en la región esteparia de Tierra del Fuego, entre la bahía San Sebastián y Río Grande. La primera en aparecer sería la estancia Sara según la identificación de Mateo Martinic y Samuel Garcia Oteiza, comparando imágenes de la película con fotografías (Anónimo, 1920; Fuentes Rabé, 1923). También es posible que algunas imágenes fueran filmadas en la misión La Candelaria, ubicada muy cerca de allí.

Cinco selk'nam aparecen en la película: un hombre y cuatro mujeres, todos vestidos al modo europeo. Se reconoce a Angela Loij, conocida por las fotografías de Gusinde e informante de la etnóloga Anne Chapman, 40 años más tarde (Fig. 10).

10 Un campement d'Indiens patagons nous est signalé. Ils viennent là pour faire un peu de commerce avec les gens de la ville, mais on ne leur donne pas le droit d'entrer à Ushuaïa. Ils campent dans de petites îles en face, et la plupart du temps les habitants de la ville vont les trouver, car ils vendent de tout : des travaux de vannerie faits par les femmes, du poisson pêché par les hommes, moutons et volailles élevés par eux.

11 La identificación de las personas fue establecida gracias a la colaboración de María Luisa Muñoz y Francisco Filgueira Martínez, miembros de la Comunidad yagán de Puerto Williams. 

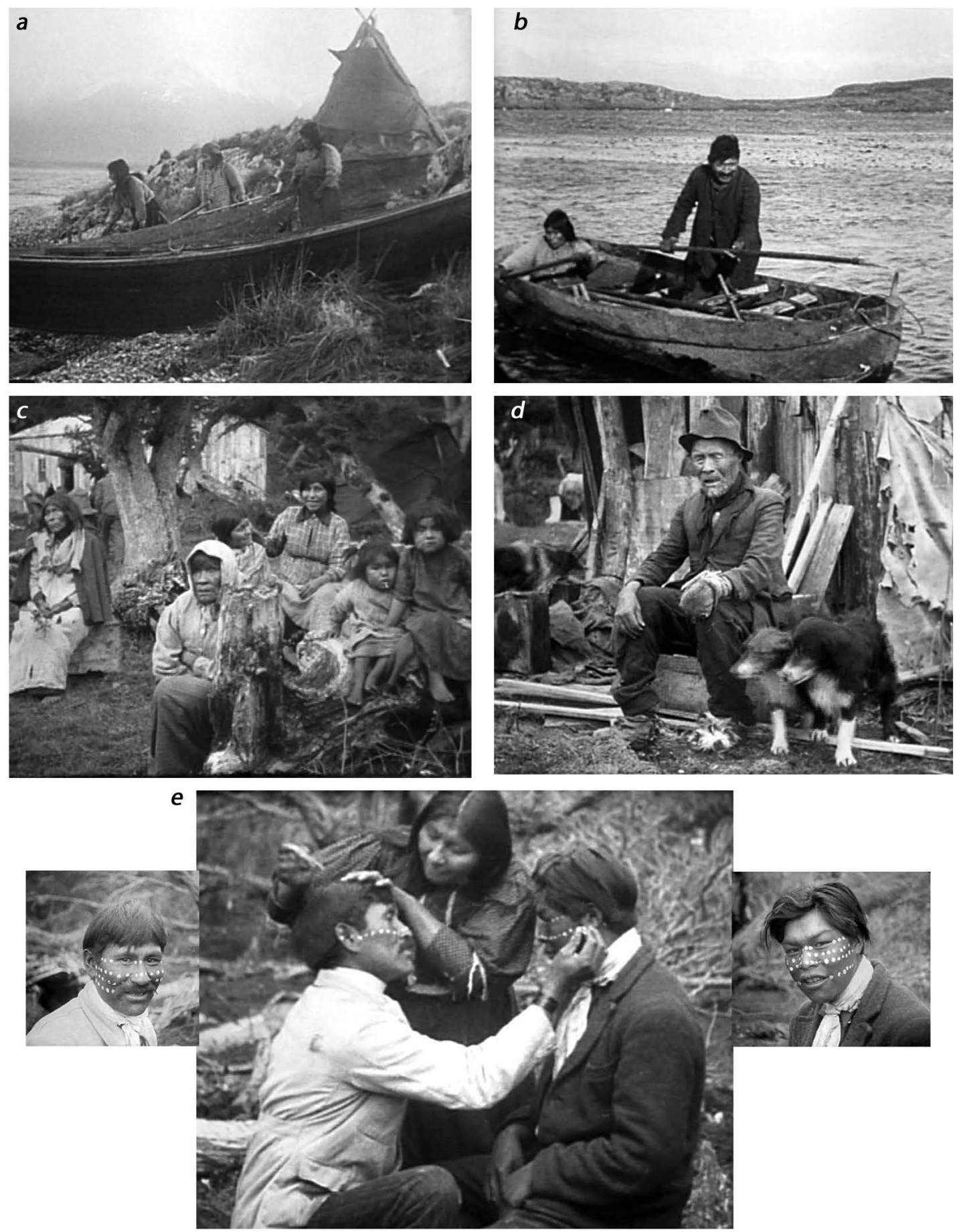

Fig. 9 Los yaganes: a) Ethel, Mary/Yayosh y Julia/Carrupako le kipa empujan una canoa al agua; b) Julia/Carrupako le kipa y Chris cazando una tonina; c) grupo de mujeres con Peine/Ohmchen a la izq. y Julia/Carrupako le kipa en el primer plano; d) el anciano Whaits (o: Witch, Weitz); e) pinturas faciales con Chris (izq.), Kerty (centro) y Noah (der.). 

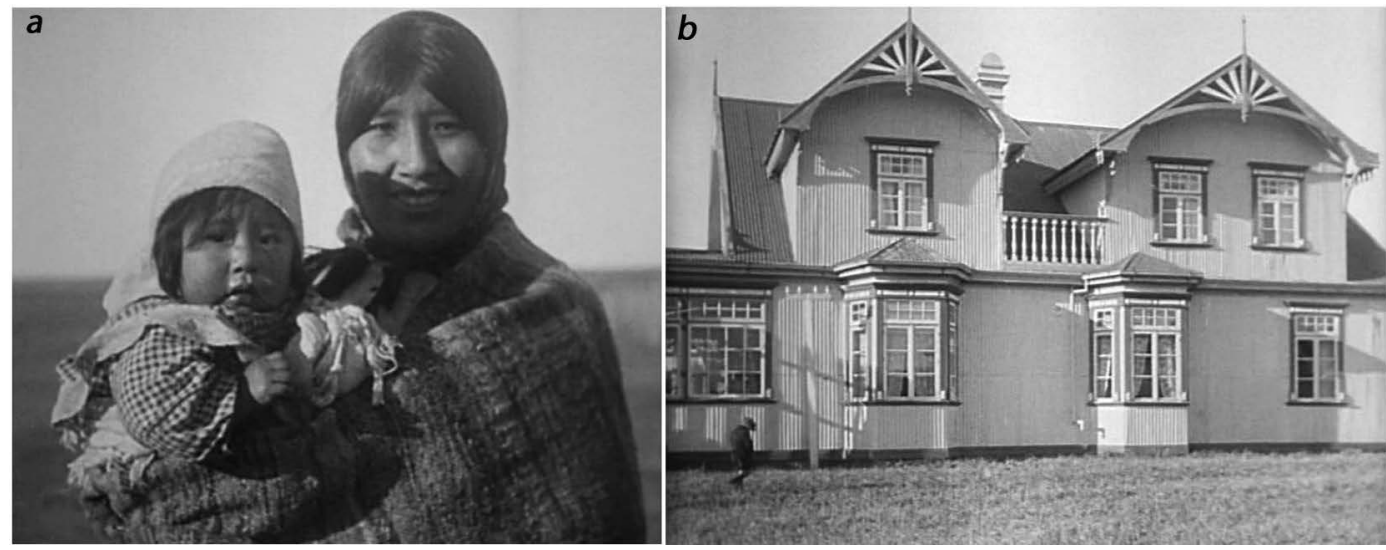

Fig. 10 Tierra del Fuego: a) Angela Loij, una selk'nam conocida de los etnólogos; b) casa patronal de la estancia Sara (fotogramas de la película La Terre de Feu).

\section{CONCLUSIONES}

Desde hace algunos años se multiplican los documentales sobre la vida indígena (Maturana, 2006). Se basan en los relatos que fueron transmitidos por los últimos descendientes y sobre los documentos visuales (fotográficos o fílmicos) del período clave 1880-1920, que fue testigo de la rápida desaparición de los modos de vida de estos cazadores recolectores, impactados por la colonización.

Sin embargo, los registros antiguos deben ser estudiados con precaución. Como hemos visto, por razones técnicas, las primeras personas fotografiadas en el siglo XIX como las de la Mission Scientifique du Cap Horn son realistas, pero están posando, generalmente de cerca. A partir de los años 1920, se disfrazan y actúan para reconstituir escenas más o menos auténticas según los deseos del operador (fotógrafo o cineasta). La película $L a$ Terre de Feu no escapa a este defecto. A pesar de todo, representa uno de los pocos testimonios animados sobre estos últimos cazadores recolectores nómades con una cultura milenaria. En particular sobre un grupo indígena menos conocido, el de los alacalufes, uno de los pocos que vivía aún una vida nómade en esta época. La mayor parte de los elementos técnicos filmados habían sido descritos por viajeros y etnólogos, y algunas personas fueron identificadas. No obstante, esta película permite observar imágenes animadas excepcionales que no pueden ser traducidas por palabras o imágenes fijas. Muestra comportamientos generalmente difíciles de aprehender, tales como las actitudes de las mujeres con sus hijos (la manera de llevarlos, acariciarlos, jugar con ellos), y también los modos de estos últimos cuando imitan las acciones de sus padres, la manera de instalarse alrededor de la fogata en la choza, cocer y comer las cholgas, descansar en la playa, agarrar el arco o remar. Es este "punctum" que describe Barthes (1980) el que focaliza el interés de las fotografías. Es también la ventaja de una película que, a pesar de una puesta en escena deseada e interpretada de manera azarosa por los directores, entrega al espectador sutiles detalles de la vida que escapan tanto a la voluntad del operador como al sujeto filmado.

\section{AGRADECIMIENTOS}

Agradecemos al Sr. Olivier Le Saint por habernos transmitido el valioso diario de su abuelo que nos permitió reconstituir el itinerario del viaje y rectificar algunos errores de la película. Igualmente nos trasmitió el guión inicial de Mandement, que se encontraba en los archivos de su abuelo.

Estamos igualmente muy agradecidos con el señor Gerd Pagels, hijo del piloto del Júpiter, quien nos facilitó una parte del diario de su padre en lo que se refiere a la expedición descripta aquí. Dicho diario fue en parte publicado en Alemania bajo el título de "Mein Leben", poco antes de la segunda guerra mundial.

$\mathrm{Y}$ por fin, un gran agradecimiento a los miembros del CNC (Centre National du Cinéma et de l'image animée) en Paris y a la Cinemateca 
de Toulouse, quienes nos permitieron utilizar esta película y en particular a Francesca Bozzano quien la redescubrió y nos entregó valiosos consejos sobre sus peculiaridades técnicas y sus autores.

\section{BIBLIOGRAFÍA}

Anónimo (1920). Ganaderia, industria y comercio del territorio de Magallanes, desde el inicio hasta la actual época 1919. Diaz y Contardi (Eds.). Punta Arenas; Santiago de Chile.

Atlas hidrografico de Chile (1989). Instituto Hidrografico de la Marina de Chile, $4^{\circ}$ ed.

Barclay, W. (1904). The land of Magallanes, with some account of the Ona and other indians. Geographical Journal, XXIII, 62-79.

Barthes, R. (1980). La chambre claire, note sur la photographie. Cahier du Cinémal, Gallimard Seuil, Paris.

Chevallay, D. (2000). Observaciones hechas en la bahia Muñoz Gamero 16.VI.2000. MS.

Chevallay, D., \& Granero, M. (2013). Scritti d'America Australe. Bibliografía di Alberto Maria De Agostini. Ed. Museo Nazionale della Montagna-CAI, Torino.

De Agostini, A. (1945). Andes Patagonicos. Viajes de exploracion a la Cordillera Patagonica austral, $2^{\circ}$ Ed.: Buenos Aires.

De Agostini, A. M. (2014). Tierra del Fuego, el film más artístico, pintoresco e instructivo de nuestro lejano sur $[35 \mathrm{~mm}]$.

Emperaire, J. (1963). Los Nómades del Mar. Santiago: Editorial Universitaria.

Fuentes Rabé, A. (1923). Tierra del Fuego, Imprenta Central E. Lampert.

Gusinde, M. (1991 [1974]). Los Indios des Tierra del Fuego. T. 3: Los Halakwulup. Buenos Aires: Centro Argentino de Etnología Americana.

Hyades, P. D. J., \& Deniker, J. (1891). Anthropologie et Ethnographie. Mission Scientifique du Cap Horn, 1882-1883, T. VII, Paris: Gauthiers-Villars.
Legoupil D. dir. (1989). Ethno-archéologie dans les Archipels de Patagonie : les Nomades Marins de Punta Baja. Mémoire de l'ADPF, ed. Recherches sur les Civilisations, 262 p.

Legoupil D., Christensen M., Laporal D., De Miranda I., Morello F., Pellé E., San Román M., \& J. Teyssandier (2014). Le parc Marin Coloane : prospection archéologique. Rapport au ministère des Affaires Etrangères, France

Legoupil, D., \& Sellier, P. (2004). La sepultura de la Cueva Ayayema (Isla Madre de Dios, archipielagos occidentales de Patagonia). Magallania, 32, 115-124.

Le Saint, L. (1925). Journal Terre des Feux. Recuperado de http://lucienlesaint.fr/TERRE_DE_FEU.html.

Mandement (1929). CR in Bulletin de la Société préhistorique de France, Tomo 26, 11, sesión del 28 de noviembre.

Mandement (s.f.). La Terre de Feu - film documentaire. Martial L.F. (1888). Histoire du Voyage. Mission Scientifique du Cap Horn, 1882-1883, T. I, Paris: Gauthiers-Villars.

Maturana, D. F. (2006). El documental fueguino chileno en el siglo XXI. Una mirada desde la antropologia visual. Magallania, 34, 59-75.

Morello, F., San Román, M., Prieto, A., Reyes, O., Bahamonde, G., Torres, J., \& Lucero, M. (2008). Línea de base de los recursos culturales y antecedentes historicos del ÁMCP Francisco Coloane : informe final. CEHA, Punta Arenas. MS.

Palma Benkhe, M. (2015). Salvar lo que queda. Antesala de la fotografía de Martin Gusinde en Tierra del Fuego. In El Espiritu de los Hombres de la Tierra del Fuego. Ed. X. Paris: Barral.

Riso Patron, L. (1924). Diccionario Jeográfico de Chile. Santiago de Chile: Imprenta Universitaria.

Skottsberg (1911). The wild of Patagonia. A narrative of swedish expedition to Patagonia, Tierra del Fuego and the Falkland islands in 1907-1909. Londres: E. Arnold.

Skottsberg C. (1913). Observations on the Natives of the Patagonian Channel Region. American Anthropologist, 15(4), 578-616. 